\title{
Further observation of Hemoglobin Fontainebleau (a21(B2) Ala-Pro) in a Turkish family
}

Nejat Akar ${ }^{1}$, Serdar Ceylaner ${ }^{2}$, Yasemin Ardicoglu Akisin ${ }^{3^{*}}$ (D) and Gokce Su Tastan ${ }^{4}$

To the Editor,

Several hemoglobin $(\mathrm{Hb})$ variants have been reported in Turkish population [1-3]. Herein, we represent a nucleotide alteration of the alpha-2 chain variant, Hemoglobin Fontainebleau (a21(B2) Ala-Pro) in an 8year-old male Turkish child living in Ankara, Turkey. He was admitted to the Hospital Pediatrics Department for routine check-up. His physical examination was normal, and there was no positive consanguinity between his parents. High red blood cell count and low mean corpuscular volume were detected in complete blood count (CBC) (Fig. 1a). High-performance liquid chromatography (HPLC) showed an asymmetry (shoulder formation) in the descending part of A0 and in the A2 curve. Levels of $\mathrm{HbA}, \mathrm{HbA} 2$, and $\mathrm{HbF}$ were observed as $93.25 \%$, $3.55 \%$, and $1.07 \%$, respectively (Fig. 1a). His mother and 6year-old sister were also screened. Their HPLC chromatograms showed similar pattern (Fig. 1b, c).

Sequence analysis of HBA1 and HBA2 genes were performed by using MiSeq next-generation sequencing (NGS) platform (Illumina, San Diego, CA, USA). Genomic DNA was extracted by using the QIAamp DNA Blood Midi Kit (Qiagen, Hilden, Germany). All coding regions and exon-intron boundaries of the genes were amplified using PCR primers, designed with PRIMER@Primer Designer v.2.0 (Scientific \& Educational Software programme) software. Alignment was done by using hg19 genome with MiSeq Reporter software (Illumina Inc.), and analysis was done with IGV 2.3 (Broad Institute) software. These genes were also tested for common deletions with MLPA (multiplex ligation-dependent probe amplification) method (SALSA MLPA P140 HBA probemix, MRC Holland, Amsterdam, Holland). NM_ 000558.5(HBA1):c.64G>C (p.Ala22Pro) was detected by sequence analysis while MLPA test was normal (Fig. 1a, b).

Written informed consent for genetic analysis was obtained both from the child's parents and from the mother.

Hemoglobin Fontainebleau (a21(B2) Ala-Pro) is a rarely reported hemoglobin variant. It was first reported in an Italian family without DNA analysis in 1989 and later on in India, Canada, South Cyprus, United Arab Emirates, Iraq (family living in New Zealand), and Turkey. It was described as a silent mutation and was also reported in combination with heterozygote forms of sickle cell, hereditary spherocytosis, and Hb Punjab [1, 4-6].

It is interesting that the cases identified were on historical migration routes. Since Turkey is located at the intersection of two continents, it is not surprising that many different hemoglobin variants are observed. Further observation of Hb Fontainebleau (a21(B2) Ala-Pro) suggests that this variant is found sporadically in the Turkish population.

\footnotetext{
* Correspondence: yardicoglu@gmail.com

${ }^{3}$ Department of Biochemistry, Faculty of Medicine, TOBB Economy and Technology University, Yasam Cad. No5 Sogutozu, 06510 Ankara, Turkey Full list of author information is available at the end of the article
} 


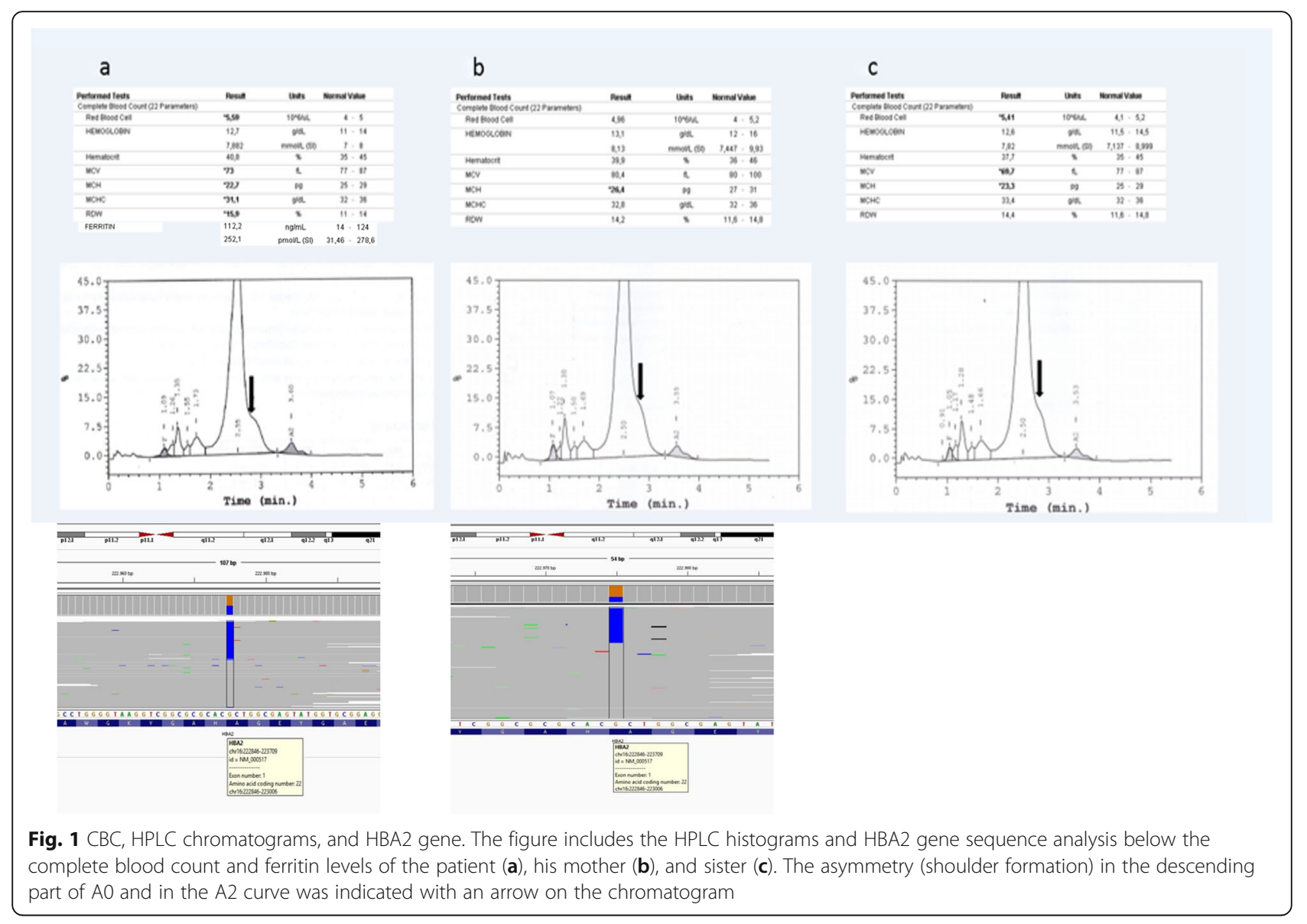

\section{Abbreviations}

CBC: Complete blood count; Hb: Hemoglobin; HPLC: High-performance liquid chromatography; MLPA: Multiplex ligation-dependent probe amplification; NGS: Next-generation sequencing

\section{Acknowledgements}

Not applicable.

\section{Authors' contributions}

NA contributed to the clinical diagnosis and reviewing of the manuscript. SC contributed to the sequence analysis. YAA contributed to the drafting and reviewing of the manuscript. GST contributed to the drafting of the manuscript. All authors have read and approved the final manuscript.

\section{Funding}

No funding was received.

\section{Availability of data and materials}

The authors can confirm that all relevant data are included in the manuscript.

\section{Ethics approval and consent to participate}

Each author has participated sufficiently in the work to take public responsibility for the content, and also, the authors had no conflict of interest to declare in relation to this manuscript. As it was a retrospective study, ethics approval was not taken.

\section{Consent for publication}

Written informed consent for genetic analysis and publication was obtained from the patient's family.

\section{Competing interests}

The authors declare that they have no competing interests.

\section{Author details}

${ }^{1}$ Department of Pediatrics, Faculty of Medicine, TOBB Economy and Technology University, Ankara, Turkey. ${ }^{2}$ Intergen Genetic Centre, Ankara, Turkey. ${ }^{3}$ Department of Biochemistry, Faculty of Medicine, TOBB Economy and Technology University, Yasam Cad. No5 Sogutozu, 06510 Ankara, Turkey. ${ }^{4}$ Gokce Su TASTAN, TOBB Economy and Technology University, Faculty of Medicine, 5th year Student, Ankara, Turkey.

Received: 5 October 2019 Accepted: 9 January 2020

Published online: 20 January 2020

\section{References}

1. Altay C (2002) Abnormal hemoglobins in Turkey. Turk J Haematol 19:63-74

2. Akar E, Akar N (2007) A review of abnormal hemoglobins in Turkey. Turk J Hematol 24:143-145

3. Akar N (2014) An updated review of abnormal hemoglobins in the Turkish population. Turk J Haematol 31(1):97-98

4. Wajcman H, Blouquit Y, Gombaud-Daintonge G, Riou J, Galacteros F (1989) Hb Fontainebleau alpha 21(B2)Ala-Pro, a new silent mutant hemoglobin. Hemoglobin 13:421

5. Upadhye DS, Jain D, Nair SB, Nadkarni AH, Ghosh K, Colah RB (2012) First case of Hb Fontainebleau with sickle haemoglobin and other non-deletional a gene variants identified in neonates during newborn screening for sickle cell disorders. J Clin Pathol 65:654-659

6. Rodríguez-Capote K, Estey MP, Barakauskas V, Bordeleau P, Christensen CL, Zuberbuhler P, Higgins TN (2015) A novel double heterozygous Hb Fontainebleau/HbD Punjab hemoglobinopathy. Clin Biochem 48(13-14):904-907

\section{Publisher's Note}

Springer Nature remains neutral with regard to jurisdictional claims in published maps and institutional affiliations. 